\title{
Energy and Stiffness of Mine Models and Seismicity
}

\author{
S.M. Spottiswoode CSIR, South Africa
}

L.M. Linzer Meerkat cc, South Africa

S. Majiet CSIR, South Africa

\begin{abstract}
We analysed seismicity in two deep gold mines in terms of strain energy release during mining. Mining took place with regularly-spaced dip pillars and backfill for regional support. The mines were chosen to represent mining of the Carbon Leader reef (CLR) and the Ventersdorp Contact reef (VCR). More than $500,000 \mathrm{~m}^{2}$ of reef were mined over several years and generated more than 10,000 events of magnitude greater than 0.0 in each case.

Most seismicity was located close to faces that were actively mined, at least within the assumed location error of $50 \mathrm{~m}$. Software was developed to associate seismic events with faces that were mined during the same month, or if not close to active faces, with stationary faces or abutments. Areas of mining that were active in each month and that were more than $100 \mathrm{~m}$ from any other active mining were grouped together to form over 300 discrete seismogenic regions, or polygons for each month of mining. Mining and seismicity data were cumulated in various ways including cumulating values for data sorted by increasing values of energy release rate (ERR) computed numerically and averaged over each polygon. The most obvious result was that cumulated seismicity was more clearly proportional to cumulated strain energy release than to cumulative area mined, supporting the use of minimisation of ERR as an effective rockburst control method when ERR is calculated from the ratio of strain energy release to area mined.

The linear relationship between cumulated seismicity and cumulated strain energy was maintained even when the reef was assumed to yield at normal stress of $300 \mathrm{MPa}$ and more. It was only when modelled pillar strength was reduced to $250 \mathrm{MPa}$ or less at both mines, that the models released excessive strain energy release at high values of ERR. It is possible that the design criterion of $400 \mathrm{MPa}$ for pillar strength applied on one mine was conservative.

The role of geological structures on seismicity was not the focus of this paper as mining in the vicinity of these structures took place at all spans and therefore at all values of ERR. In a separate study we showed that geological structures contribute $50 \%$ or less of the total amount of seismicity.

The apparent stress and the ratio of seismic moment derived from $P$-waves to that derived from $S$-waves were found to vary with ERR, with both decreasing with increasing ERR for data from mining of the CLR, while the apparent stress increased with increasing ERR for VCR mining, as expected for the generally increasing levels of stress ahead of the advancing faces. We suggest that the decrease in values for the CLR data might be attributable to a more extensive fracture zone resulting from bedding-plane slip than occurs around the VCR with its massive lava hangingwall. We propose a simple softening model to explain the CLR behaviour.
\end{abstract}

\section{Introduction}

Deep-level mining of tabular reefs uses regional support to control seismicity. Many of the deep workings in the Carletonville gold mining district in South Africa have moved from strike stabilizing pillar systems to pillars and backfill for regional support (McGill, 2005; Klokow et al., 2003).

Pillar mining is being practised mostly in two forms, namely Sequential Grid Mining (Handley et al., 2000) and Closely Spaced Dip Pillar Mining (Klokow et al., 2003). This paper forms part of a project to study seismicity around dip pillar mining in deep-level gold mines. 


\subsection{Energy release rate (ERR) and average pillar stress (APS)}

The concept of energy release associated with the incremental enlargement of tabular excavations was proposed in the landmark paper of Cook et al. (1966). They also pointed out that the amount of energy release per area mined could be reduced through the application of regional pillars. This led to the use of stabilising pillars aligned along strike (van Antwerpen and Spengler, 1982; McGarr and Wiebols, 1977) as a way of reducing the amount of seismicity and rockbursts. Stabilising pillars are now mostly aligned along dip (Handley et al., 2000; Klokow et al., 2003; McGill, 2005).

The 'seismic energy efficiency' $(\eta)$ of converting strain energy release to seismicity has been measured (McGarr et al., 1979; Spottiswoode, 1980). They showed that less than 1\% of the strain energy released during two seismic events was radiated seismically, a figure similar to that proposed for earthquakes.

Although the number of rockbursts per area mined was found to be proportional to ERR (Jager and Ryder, 1999), Ryder and Jager (2002) veered away from recommending the use of ERR as an indicator of seismicity, preferring to advocate its use as a measure of underground conditions. They were influenced by two factors in coming to this conclusion: recent unreferenced data with limited range of ERR values that showed very little or no correlation of seismicity with ERR level; and their own difficulties with reconciling the very low proportion of elastic strain energy that is released by seismically radiated energy. Instead Ryder and Jager (2002) focussed attention on the use of ESS as the most appropriate way to model seismicity, with particular focus on slip on pre-existing geological faults.

ERR was calculated in two ways in this paper. For areas being actively mined, ERR was calculated from the ratio of strain energy release to area mined: for a single 'elastic' element, ERR $=1 / 2 \mathrm{x}$ stress before mining $\mathrm{x}$ convergence after mining. For stationary faces, ERR $=1 / 2 x$ stress ahead of face $x$ convergence behind face.

Pillars are designed to hold up the entire weight of overburden and must therefore be assumed to have a certain strength, or load-carrying capability. The in situ strength of these regional pillars is still not well known. Ryder and Jager (2002) mentioned a range of possible strengths (from 500 down to $240 \mathrm{MPa}$ ).

A large part of this paper is dedicated to careful consideration of whether or not ERR is indeed a useful predictor of seismicity. The APS criterion is tested by considering seismicity as a function of strain energy released if unmined areas are allowed to yield at different strengths.

\subsection{Interaction amongst mine events and other fractures}

The stress field induced by deep-level mining is so high that fracturing and seismicity are common. Tabular stopes in brittle rock are surrounded by a fracture zone (Figure 1) that increases in size with increasing levels of ERR (Ryder and Jager, 2002).

From a seismological perspective, the ensemble of seismic events plays a major role in relaxing stresses ahead of the face and is thought to occur through development and mobilisation of shear fractures, marked 'Type II' and ' $S$ ' in Figure 1(a). These interact with induced tensile fractures and joints 'Type I' and parting (bedding) planes. For the purposes of this paper, an equivalent fracture zone can be drawn (Figure 1(b)) to consist of seismic sources (S1 and S2) and a diffuse fracture zone that forms ahead of the face. As mining of the reef advances through this fracture zone, it forms the hangingwall and footwall of the stopes. Because falls of ground and rockbursts occur when this region fails, its behaviour is of great importance to mining.

Ortlepp (1997) mapped a series of interacting shear zones, some of which intersected one another and others that were closer together $(<5 \mathrm{~m})$ than their spatial extent $(>20 \mathrm{~m})$. Two shear zones that were most carefully studied formed ahead of the face, as in zone S2 Figure 1(b). Napier (1991) showed that a 'daylighting' shear plane (S1) should slip about ten times more than a shear plane that intersects the reef ahead of the face (S2) in an elastic rock mass. In more recent, unpublished work, Napier (2008, pers. comm.) showed that S2-type slip could force or mobilise a series of fractures into the stope if the vertical extent of slip was substantially more than its distance ahead of the face.

Malan et al. (2003) studied convergence between points on the hangingwall and footwall of stopes within our study area at Mine B. Both blasting and seismicity appeared to have added very rapid stope convergence followed by an increased rate of convergence to a constant background rate. In contrast, Share (2007) reported on an apparently complete lack of post-seismic tilting, as observed $90 \mathrm{~m}$ off reef. This suggests that 
the fracture zone shows a delayed response to the loads imposed by mining and seismicity. Face preconditioning (Toper, 2007) is routinely applied on some mines to reduce rockburst damage. Its mechanism appears to be based on a highly generalised picture of the fracture zone and its behaviour. In summary, very little is known about the interaction between the fracture zone and seismic shear zones occurring ahead of the face.
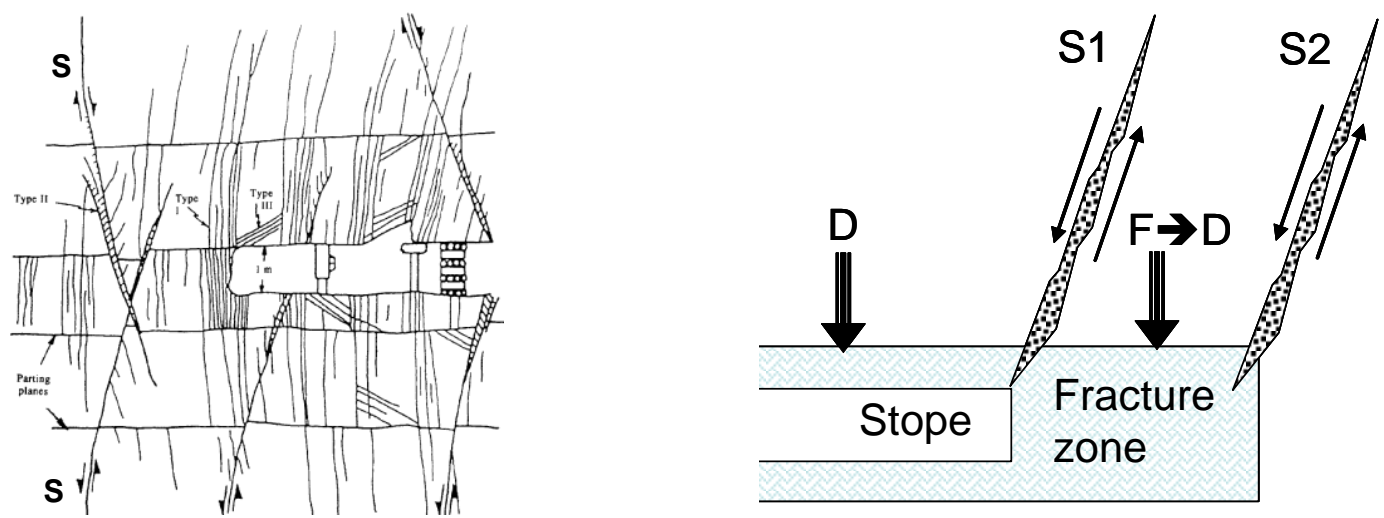

Figure 1 (a) Cartoon of fracturing around an advancing face (Adams et al., 1981); (b) a simplified version of (a) showing two shear fractures, a fracture zone and force and displacement vectors driven by slip on shear zone $\mathrm{S} 2$

In addition to studying seismicity as a possible function of ERR, we looked for changing character of seismicity in terms of apparent stress $\left(\tau_{\mathrm{a}}=\mathrm{G} \times \mathrm{E}_{\mathrm{S}} / \mathrm{M}_{0}\right.$ :, where $\mathrm{G}$ is the modulus of rigidity $30 \mathrm{GPa}$, $\mathrm{E}_{\mathrm{S}}$ is radiated energy and $\mathrm{M}_{0}$ is the seismic moment: Table 3 ) and the ratio of seismic moments derived from $\mathrm{P}$ waves to moments derived from $\mathrm{S}$-waves (P/S moment ratio). The expectation was that apparent stress would increase with increasing ERR and elastic stresses ahead of the face. P/S moment ratio should be 1.0 on average for pure shear slip but Spottiswoode et al. (2006) found values well in excess of 1.0 for events associated with failure of small pillars in a mine in the Bushveld Complex. Boettcher et al. (2008) reported that $\mathrm{M}>2$ events had $\mathrm{P} / \mathrm{S}$ moment ratio of 1.0 while smaller events showed moderate to significant implosive components. A stiffness model was developed for this project to assist in analysing data for this study.

\section{Case studies}

We studied seismicity in terms of elastic and plastic deformations associated with mining at two mines, Mine A on the Carbon Leader reef (CLR) and Mine B on the Ventersdorp Contact reef (VCR). Of particular interest in this study is that the CLR host rocks are more bedded than those of the VCR and therefore the stress fracture zone ahead of the CLR is deeper and more mobile than is the case for the VCR (Jager and Ryder, 1999).

These areas were chosen partly because they were not structurally complex, with none of the faults causing major departure from planarity of the reef. Mine A was bounded on one side by a syncline with associated anomalous stresses and our study area was chosen to avoid this structure. The effect of the geological discontinuities has been studied and we found that the total amount of seismicity was, on average, between 38 and $100 \%$ higher due to geological structures in Mine A and between 0 and $29 \%$ higher at Mine B. The lower values were measured when seismicity was quantified in terms of the number of events and the higher values when seismicity was quantified in terms of radiated energy. More geologically-associated seismicity might have occurred had mine layouts not been planned around the geological structures.

The basic data for this study were obtained from mine plans at a scale of 1:1000 and catalogues of seismic data. The reef was very planar as could be seen from the consistent orientation (along dip) and spacing (down dip) of crosscuts and their intersections to reef. We were then able to approximate the reef geometry as a plane in each case, simplifying the modelling of deformations and stresses. Plastic failure ahead of the face and abutments was modelled by using a cap, or limiting, stress on reef elements (Spottiswoode, 1997). 
The face positions showing monthly face advance over several years were digitised and converted into arrays of square elements, each representing the amount of mining in each month using the MinSim 2000 software that was developed in-house and is now proprietary software. Mining parameters are shown in Table 1 and mine outlines in Figure 2. The study areas were chosen to contain a considerable amount of mining as well as being as isolated as possible from surrounding mining. This was not entirely the case and Figure 2 also shows regions of mining and seismicity that were excluded from this study. Seismic data close to adjacent mining ' $\mathrm{O}$ ' and more than $100 \mathrm{~m}$ from any previous mining ' $\mathrm{F}$ ' were excluded from further analysis.

Table 1 Mining and layout design for two case studies

\begin{tabular}{lcc}
\hline & Mine A & Mine B \\
\hline Area mined & $1,057,896 \mathrm{~m}^{2}$ & $543,636 \mathrm{~m}^{2}$ \\
Number of mining steps digitised & 86 & 47 \\
Reef type & CLR & VCR \\
Dip angle & $24^{\circ}$ & $24^{\circ}$ \\
Designed pillar size & $40 \mathrm{~m}$ & $30 \mathrm{~m}$ \\
Centre to centre spacing & $180 \mathrm{~m}$ & $210 \mathrm{~m}$ \\
Maximum percentage extraction & $78 \%$ & $86 \%$ \\
Average depth below surface & $\sim 3200 \mathrm{~m}$ & $\sim 3400 \mathrm{~m}$ \\
\hline
\end{tabular}

The seismic catalogues contained the date, time, location and seismic energy and seismic moment for each event. The energy was reported separately for P-waves and S-waves and the seismic moment was estimated separately for the P and S phases and assumed to be a pure shear source. Quality checks were performed and corrections made. About six weeks were missing from one data set, resulting in our rejection of two months of data. Some values of seismic energy were also unrealistically large, leading to values of apparent stress in excess of $50 \mathrm{MPa}$. These appeared to have been outliers and we limited seismic energies to values derived from seismic moment and apparent stress of $3 \mathrm{MPa}$ using $\mathrm{E}_{\mathrm{S}} \leq 3 \mathrm{MPa} \times \mathrm{M}_{0} / \mathrm{G}$.
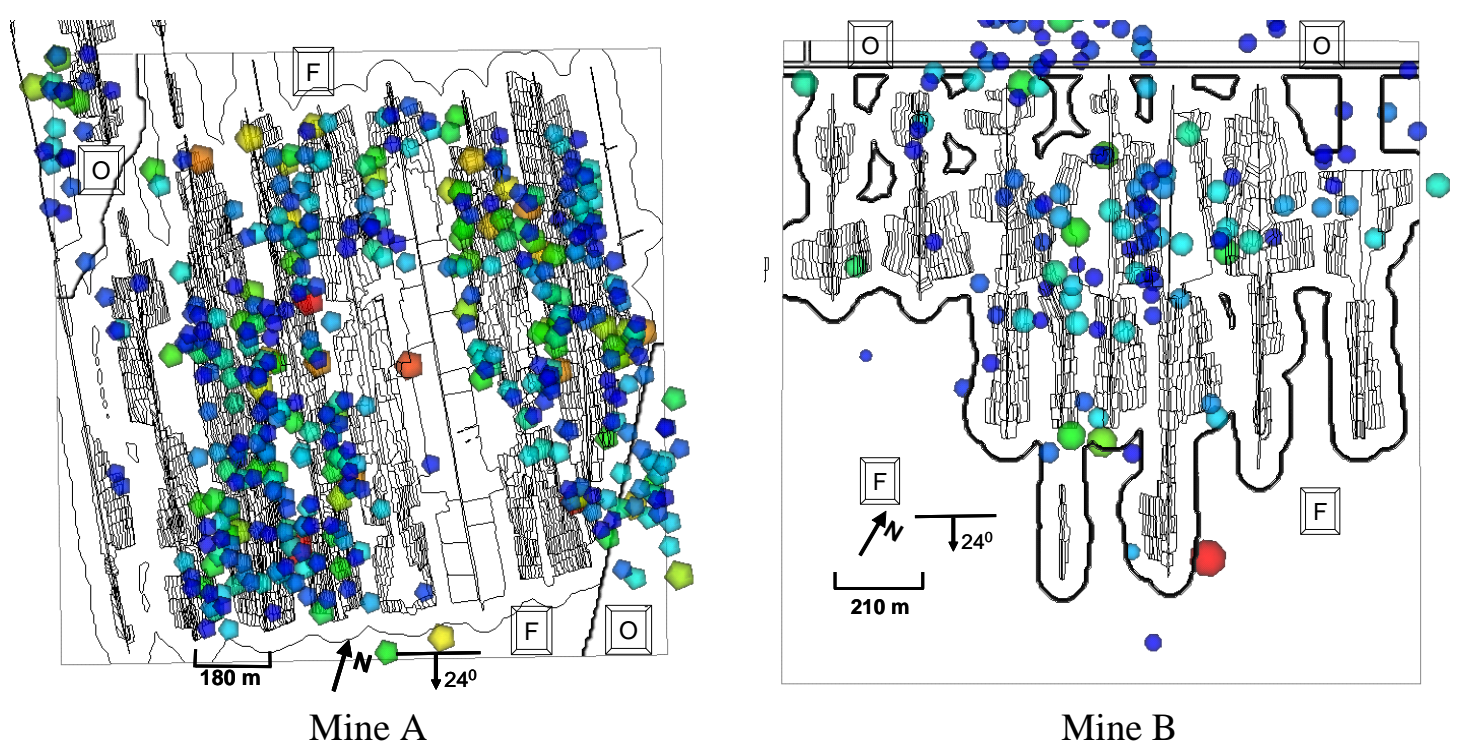

Figure 2 Mining and seismic events with magnitude $M>2.0$. Seismic events in areas marked ' $O$ ' and ' $F$ ' were excluded as they were considered to have been associated with mining outside the modelled area or were more than $100 \mathrm{~m}$ from any mining 


\section{Analysis}

\subsection{Introduction}

We based our analysis on software and methods described by Spottiswoode (2005) to analyse the amount of seismicity in terms of modelled deformations. Significant extensions were developed during the current study. Deformations were modelled on a monthly basis using the custom-built MINF code. MINF generated output that described spatial distributions of area mined and strain energy released. Area mined, strain energy release and equivalent volume of convergence between the stope roof and floor were cumulated in defined polygons. The loading stiffness driving the deformations within each polygon was calculated. The MINSINT program allocated seismicity to active mining and stationary faces. MINSINT then cumulated and listed values within polygons to be used to compare seismicity to modelled deformations.

\subsection{The modelling solution (MINF)}

The 'size' of the simulations was 256 x 256 square elements. The MINF code solves the elastic convergence and stress on each element within an elastic rock mass. Stope closure was limited by backfill that provided resistance $(\sigma)$ according to the hyperbolic function $\sigma=\frac{a \varepsilon}{b-\varepsilon}$ where $a$ and $b$ are constants (Table 2) and $\varepsilon$ is the strain on the backfill as the roof and floor converge towards one another. The modelled stope width was reduced by $0.2 \mathrm{~m}$ from the actually mined width to account for bulking of the fracture zone, as recommended by Ryder and Jager (2002).

Table 2 Modelling parameters for two case studies

\begin{tabular}{lcc}
\hline & Mine A & Mine B \\
\hline Number of elements & $256 \times 256$ & $256 \times 256$ \\
Element size & $6 \times 6 \mathrm{~m}$ & $6 \times 6 \mathrm{~m}$ \\
Youngs modulus & $70,000 \mathrm{MPa}$ & $70,000 \mathrm{MPa}$ \\
Poissons ratio & 0.2 & 0.2 \\
$\mathrm{k}-$ ratio (horizontal/vertical field stress) & 0.5, isotropic & 0.5 , isotropic \\
Backfill placement & Full height where placed & Full height \\
Backfill 'a' and 'b' values & $10 \mathrm{MPa}$ and 0.40 & $10 \mathrm{MPa}$ and 0.40 \\
\hline
\end{tabular}

On the basis that pillars will start to yield at the assumed strength, MINF limits the on-reef stress component normal to the reef plane in unmined areas to given values, called the cap stress. Initial results presented here are based on infinite strength, followed by a section in which the strength values are decreased. If the yield strength of a pillar is exceeded, considerable deformation and strain energy release is possible.

Figure 3(a) illustrates the energy released for a small step of mining (say a few metres) in an elastic environment. The rock immediately ahead of tabular deep-level stopes has been subjected to such high stresses that it has already failed or crushed and releases much less energy when actually mined. The lower the strength at the face, the more work has already been done to reduce the stress to the value. If the face is heavily fractured, as is commonly observed in deep-level stopes, then the stress might have dropped substantially. In that case, practically all of the strain energy has already been released (Figure 3(c)). Ryder and Jager (2002) refer to a 'Salamon fracture zone' in which the stress at the face is almost zero, rising up to many hundreds of MPa about $3 \mathrm{~m}$ ahead of the face. 


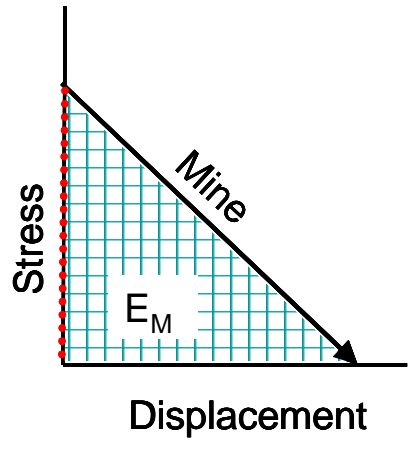

(a)

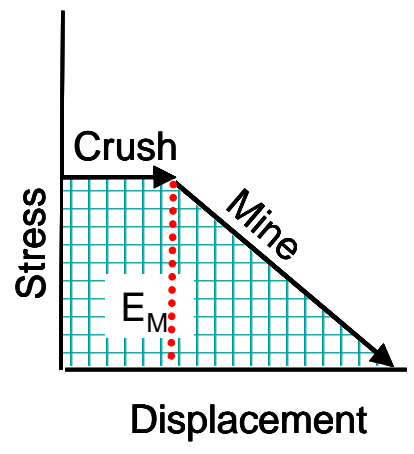

(b)

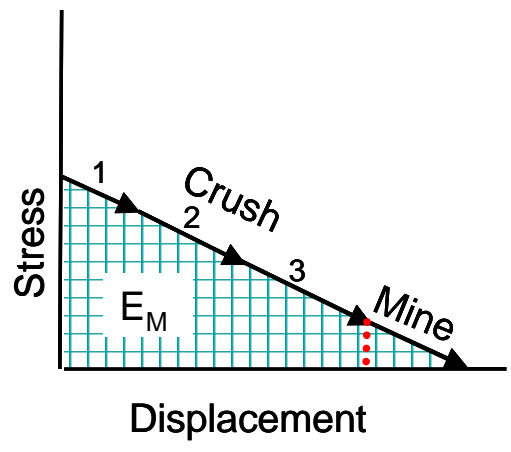

(c)

Figure 3 Sketch illustrating strain energy released by mining: (a) for elastic rock mass; (b) for a constant cap stress; and (c) for successive weakening of the fracture zone close to the face. In each case the area to the right of the dotted line represents the energy released 'at the face' during a small mining step

The MINF code provides for various types of plastic and brittle constitutive laws to approximate relaxation of the reef-normal stresses ahead of the face (Spottiswoode, 2001). The simplest of these will be applied in the paper, namely limiting, or capping, the stress to a defined level (Spottiswoode, 1997). Similar results, not shown here, were also achieved when the strength increased linearly with distance from mined-out areas.

\subsection{The integration solution (MINSINT)}

Seismicity was attributed to mining by the program MINSINT in a manner similar to that described by Spottiswoode (2005). Several factors were taken into consideration in planning the process of attributing seismicity to mining, namely:

- Seismicity is closely associated with stressed faces or abutments and more specifically with actively mined faces.

- Seismicity associated with faults or dykes also occurs under the influence of the mining.

- Seismic locations are prone to errors of about $40 \mathrm{~m}$ in the plane of the reef and much more than $40 \mathrm{~m}$ perpendicular to the plane of the reef.

- Seismic events have a finite dimension that increases with the event magnitude.

There is still no clear rule to describe the potential of stationary faces for generating seismicity. Kgarume and Spottiswoode (2008) have recently shown that the probability of aftershocks of mine events falls off as distance $\mathrm{D}^{-1.3}$ whereas quasi-static modelling predicts a fall-off rate of induced stresses of $\mathrm{D}^{-3}$. Quasi-static stress changes due to mining are therefore not always optimal as a spatial predictor of seismicity. Nonetheless, we assumed that stationary faces retain a residual propensity for failure equal to a virtual 0.01 of an element size face advance on all faces using the definition of ERR for stationary face.

Based on these considerations, the hypocentre of each event was moved to the nearest likely mining, as follows:

- Projecting it perpendicularly onto a grid point on the reef plane.

- Erecting a two-dimensional Gaussian error function around this grid point.

- Multiplying the Gaussian error function by the energy release associated with mining (Figure 3).

- Choosing the position of the maximum value of this product.

The strength of each event was then expanded according to the source size. In the example in Figure 4, Event A was moved to the nearest area of active mining while Event B was attributed to the nearest stationary face. An oblique view was used in Figure 4 and shows that Event A located further from reef than Event B. 


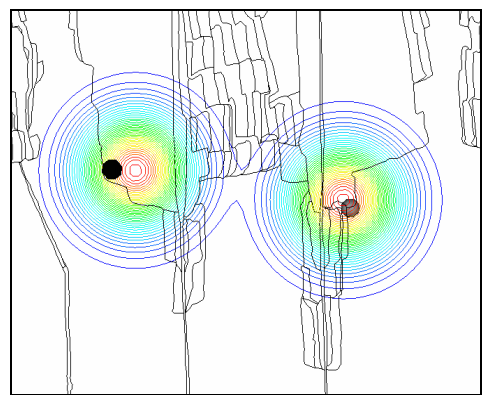

(a)

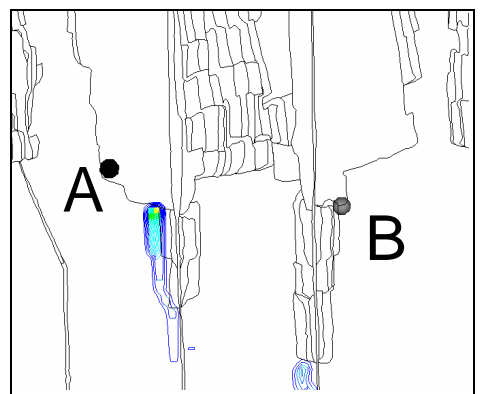

(b)

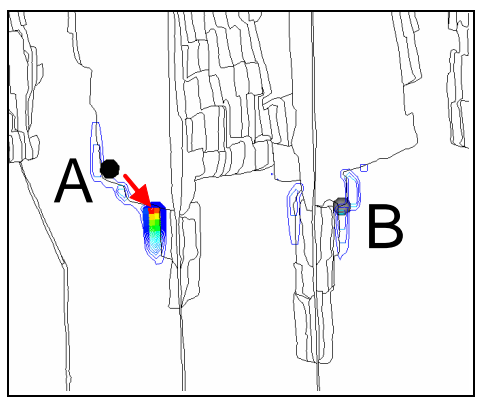

(c)

Figure 4 Diagram to illustrate how seismic Events (A and B) were attributed to mining: (a) Gaussian function around the projection of each event to reef; (b) the events with contoured released strain energy; (c) contours are the product of the values in (a) and (b). Event $A$ is moved as shown

\subsection{Grouping seismicity into polygons}

At the start of this work, polygons were defined to cover the area between raises so that mining from either side towards each final pillar position would fall into a polygon. Klokow et al. (2003) used polygons between pillars, as the area mined was available to them in this form. Unfortunately this would have led to difficulties attributing individual seismic events to the correct polygon if they located within a pillar. In contrast, we have access to the spatial distribution of all areas mined.

Cumulated seismicity is plotted for both study areas for the fixed polygons in Figure 5. Apparent volume $\left(\mathrm{V}_{\mathrm{a}}\right)$ was used as a measure of seismicity because it is commonly used in analyses of gold mine seismicity (van Aswegen, 2005) and because cumulated totals of $\mathrm{V}_{\mathrm{a}}$ are less dominated by the few largest events (Figure 7(a)). Modelling and seismicity parameters used in this Figure as well as in Figure 7 are explained in Table 3 and Table 4.

Table 3 Abbreviations used in Table 5 and Figure 5 and Figure 7 for model (M) and seismic (S) parameters

\begin{tabular}{|c|c|c|}
\hline Abbreviation & Data Type & Description, Units \\
\hline $\mathrm{A}_{\mathrm{M}}$ & M & Area, $\mathrm{m}^{2}$ \\
\hline $\mathrm{E}_{\mathrm{M}}$ & M & Strain energy released, GJ \\
\hline $\mathrm{V}_{\mathrm{E}}$ & M & Volume of elastic convergence, $\mathrm{m}^{3}$ \\
\hline ERR & M & $\mathrm{E}_{\mathrm{M}} / \mathrm{A}_{\mathrm{M}}$ \\
\hline $\mathrm{E}_{\mathrm{S}}$ & $\mathrm{S}$ & Seismic energy radiated, GJ \\
\hline $\mathrm{M}_{0}^{\mathrm{P}}$ & S & Seismic moment estimated from P-waves, MN-m \\
\hline $\mathrm{M}_{0}^{\mathrm{S}}$ & S & Seismic moment estimated from S-waves, MN-m \\
\hline $\mathrm{M}_{0}$ & $S$ & Seismic moment estimated from $\mathrm{P}$ and $\mathrm{S}$-waves, $\mathrm{MN}-\mathrm{m}$ \\
\hline $\mathrm{P}$ & $\mathrm{S}$ & Potency $=\mathrm{Mo} / \mathrm{G}, \mathrm{m}^{3}$ \\
\hline $\mathrm{V}_{\mathrm{a}}$ & $\mathrm{S}$ & Apparent volume, calculated as $\mathrm{r}^{3}, 1000 \mathrm{~m}^{3}$ \\
\hline $\mathrm{r}_{\mathrm{S}}$ & $\mathrm{S}$ & Source radius $\approx$ radius of apparent volume $=\left(3 \times \mathrm{V}_{\mathrm{a}} /(4 \times \pi)\right)^{1 / 3}, \mathrm{~m}$ \\
\hline No & $\mathrm{S}$ & Number of events when cumulated \\
\hline$\tau_{\mathrm{a}}$ & $\mathrm{S}$ & Apparent stress $=\mathrm{G} \times \mathrm{E}_{\mathrm{S}} / \mathrm{M}_{0}, \mathrm{MPa}$ with $\mathrm{G}=30 \mathrm{GPa}$ \\
\hline As & $S$ & Area of seismic slip $=\pi \times r_{S}^{2}$ \\
\hline$\eta$ & $\mathrm{M}$ and $\mathrm{S}$ & Seismic efficiency $=\mathrm{E}_{S} / \mathrm{E}_{\mathrm{M}}$ \\
\hline$\gamma_{\mathrm{E}}$ & $M$ and $S$ & Normalised seismic deformation $=\mathrm{P} / \mathrm{V}_{\mathrm{E}}, \mathrm{m}^{3}$ \\
\hline
\end{tabular}


(a)
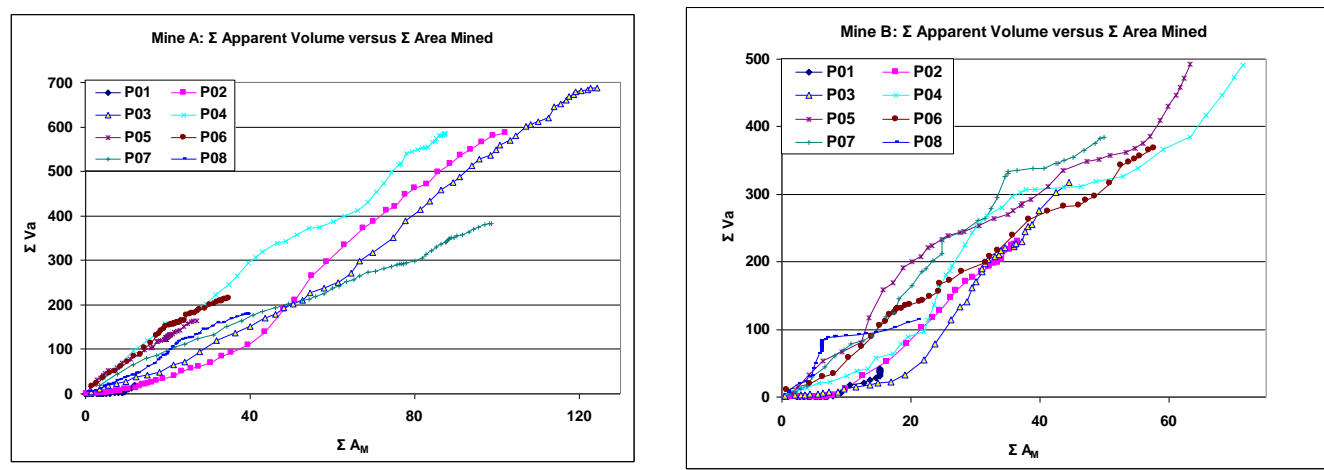

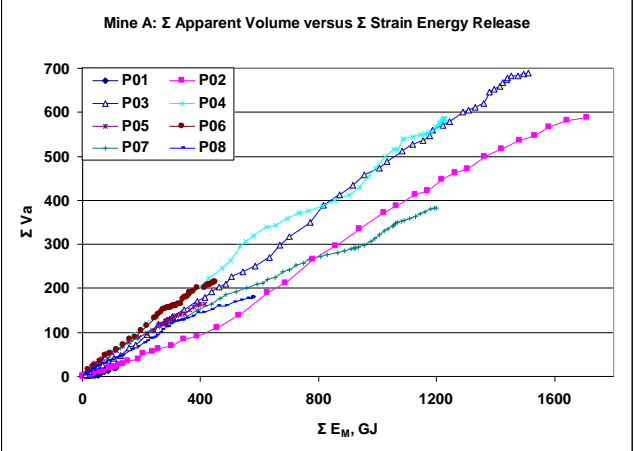

Mine A

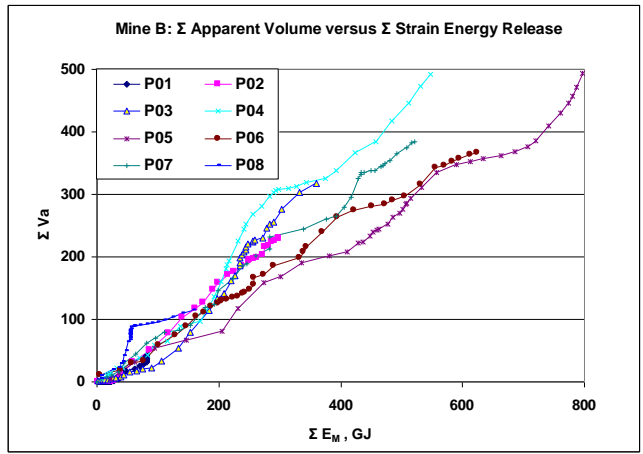

Mine B

Figure 5 Cumulated apparent volume as a function of area mined (a) and strain energy released; (b) for fixed polygons (the summation symbol $(\Sigma)$ on the axes of this figure and Figure 7 may print out as (S) on some printers)

The cumulative seismicity graphs in Figure 5 show that the seismic response for different areas within each mine is similar. The data follow trends that are quite linear for both Figure 5(a) and (b) except for part of polygon P02 for Mine A and for polygons P02 and P03 for Mine B. Data for those three polygons are curved upwards when seismicity is plotted against area mined and become linear when compared to strain energy. These polygons were therefore actually the only ones that were subject to continually increased levels of ERR.

The use of fixed polygons to group data was then changed to automatically generated polygons ('autopolys') for better isolation of groups of seismicity and mining. This also allowed for separation of seismic events into those associated with active mining from events remote from active mining.

Auto-polys were created by erecting circular regions with radii of $50 \mathrm{~m}$ around each mined element and then grouping overlapping regions together into polygons. Mined elements within each polygon were therefore at least $100 \mathrm{~m}$ from mined elements in other polygons and seismic events were unlikely to be attributed to the incorrect polygon, given the location error of about $40 \mathrm{~m}$. Figure 6 illustrates the generation of auto-polys for one month for each of the two mines using parameters listed in Table 5.

Table 4 Number of mining steps and auto-polygons for each study area

\begin{tabular}{lcc}
\hline Mine & Mine A & Mine B \\
\hline Mining steps (months) & 53 & 42 \\
Total number of polygons & 593 & 374 \\
\hline
\end{tabular}




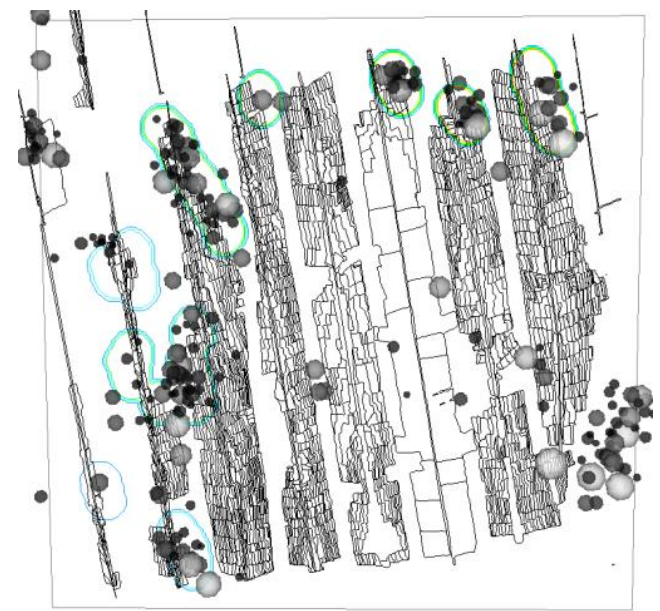

Mine A

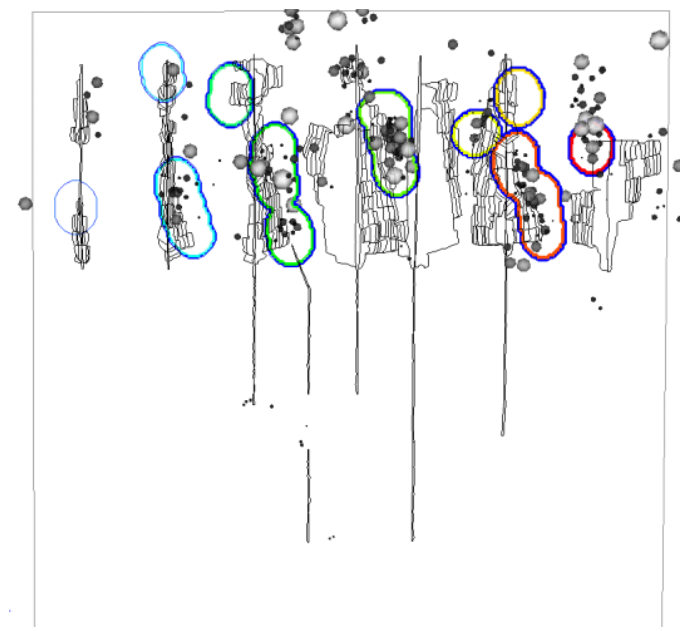

Mine B

Figure 6 Sample showing auto polygons drawn around one month's mining and seismicity during the same month

Table 5 Values used for graphs in Figure 7 and their interpretation. In each case values from each polygon are sorted by increasing ERR and cumulated for model ( $\mathrm{X}$ axis) and seismic data (Y axis)

\begin{tabular}{|c|c|c|c|c|c|}
\hline \multirow[b]{2}{*}{ Label } & \multirow[b]{2}{*}{$X$} & \multirow[b]{2}{*}{ Y } & \multirow[b]{2}{*}{ Phenomenon } & \multicolumn{2}{|c|}{ Values } \\
\hline & & & & Mine A & Mine B \\
\hline (a) & $\Sigma \mathrm{A}_{\mathrm{M}}$ & $\begin{array}{l}\text { Several seismic } \\
\text { measures, normalised }\end{array}$ & $\begin{array}{l}\text { Seismicity rate increases with } \\
\text { increasing span }\end{array}$ & N/A & N/A \\
\hline (b) & $\Sigma \mathrm{E}_{\mathrm{M}}$ & to total of $100 \%$ & Seismicity/area mined $\alpha$ ERR & N/A & N/A \\
\hline (c) & $\Sigma \mathrm{E}_{\mathrm{M}}$ & $\Sigma \mathrm{E}_{\mathrm{S}}$ & $\eta$ (seismic energy efficiency) & 0.0042 & 0.0020 \\
\hline (d) & $\Sigma \Delta \mathrm{V}_{\mathrm{E}}$ & $\Sigma \mathrm{P}=\Sigma \mathrm{M}_{0} / \mathrm{G}$ & $\gamma_{\mathrm{E}}$ & 0.25 & 0.19 \\
\hline (e) & $\Sigma \mathrm{A}_{\mathrm{M}}$ & $\Sigma \mathrm{A}_{\mathrm{S}}$ & $\begin{array}{l}\text { Overlapping source regions } \\
=\Sigma \mathrm{A}_{\mathrm{S}} / \mathrm{A}_{\mathrm{M}}\end{array}$ & 73 & 67 \\
\hline & & \multicolumn{2}{|c|}{ Apparent stress: $\Sigma\left\{\mathrm{A}_{\mathrm{s}} \mathrm{x} \tau_{\mathrm{a}}\right\} / \Sigma \mathrm{A}_{\mathrm{s}}, \mathrm{MPa}$} & 0.20 & 0.13 \\
\hline & & \multicolumn{2}{|c|}{ Overlap x apparent stress, $\mathrm{MPa}$} & 15 & 9 \\
\hline
\end{tabular}

\subsection{Cumulated seismicity plots}

Each graph in Figure 7(a) to (e) can be interpreted in terms of the response of the rock mass to mining.

The concave upwards shape of the graphs in Figure 7(a) indicate that the rate of seismicity per areas mined (the slope of the graphs) increased with increasing levels of ERR. The least pronounced increase was for the event rate for Mine A, perhaps indicating a steady growth of the fracture zone as mining advanced.

Figure 7(a) and (b) show much more contrast between them than was the case for Figure 5(a) and (b). This contrast shows that seismicity per area mined is sensitive to changes in ERR. More particularly, the clustering of the graphs in Figure 7(b) about the constant rate of seismicity given by the dot-dashed lines is compatible with seismicity per area mined being proportional to ERR. 
(a)
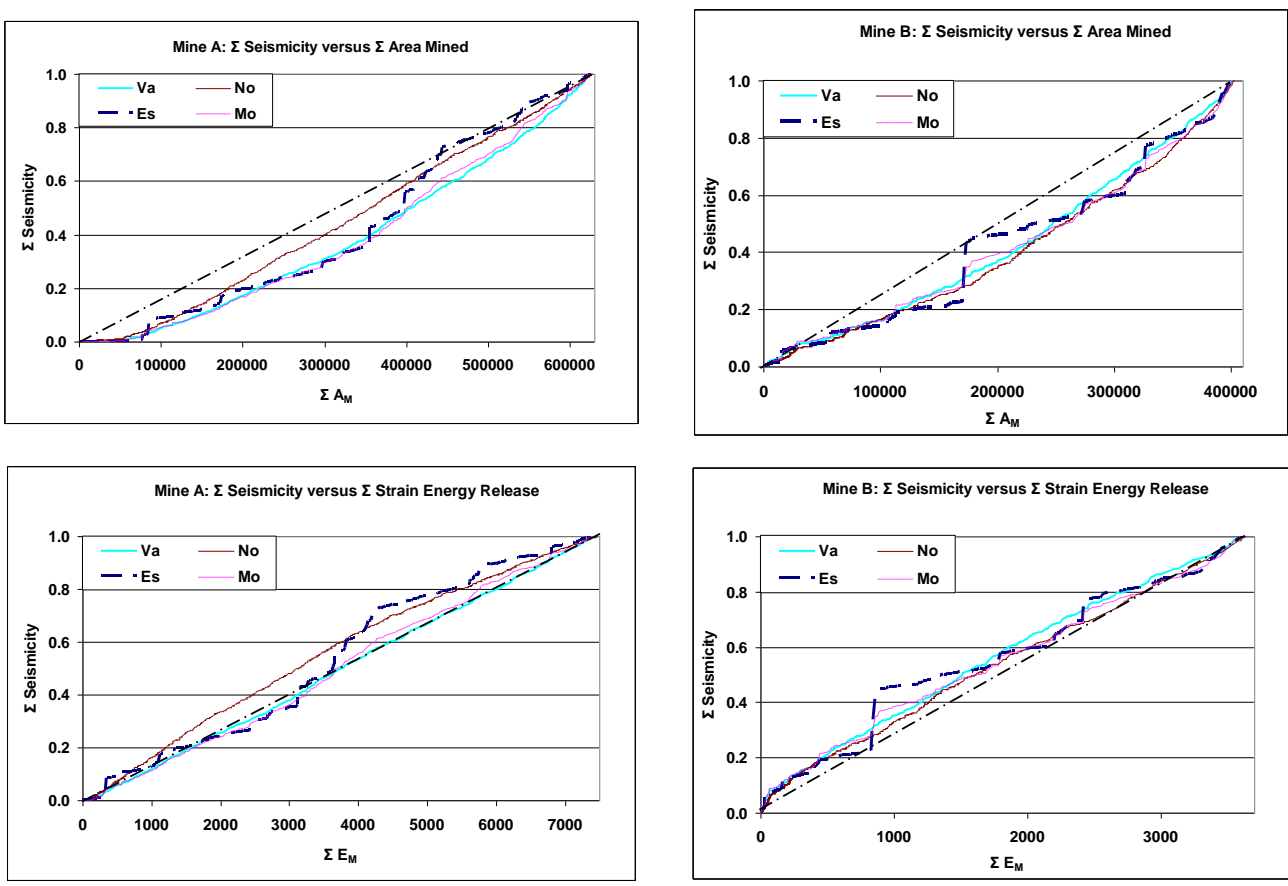

(c)
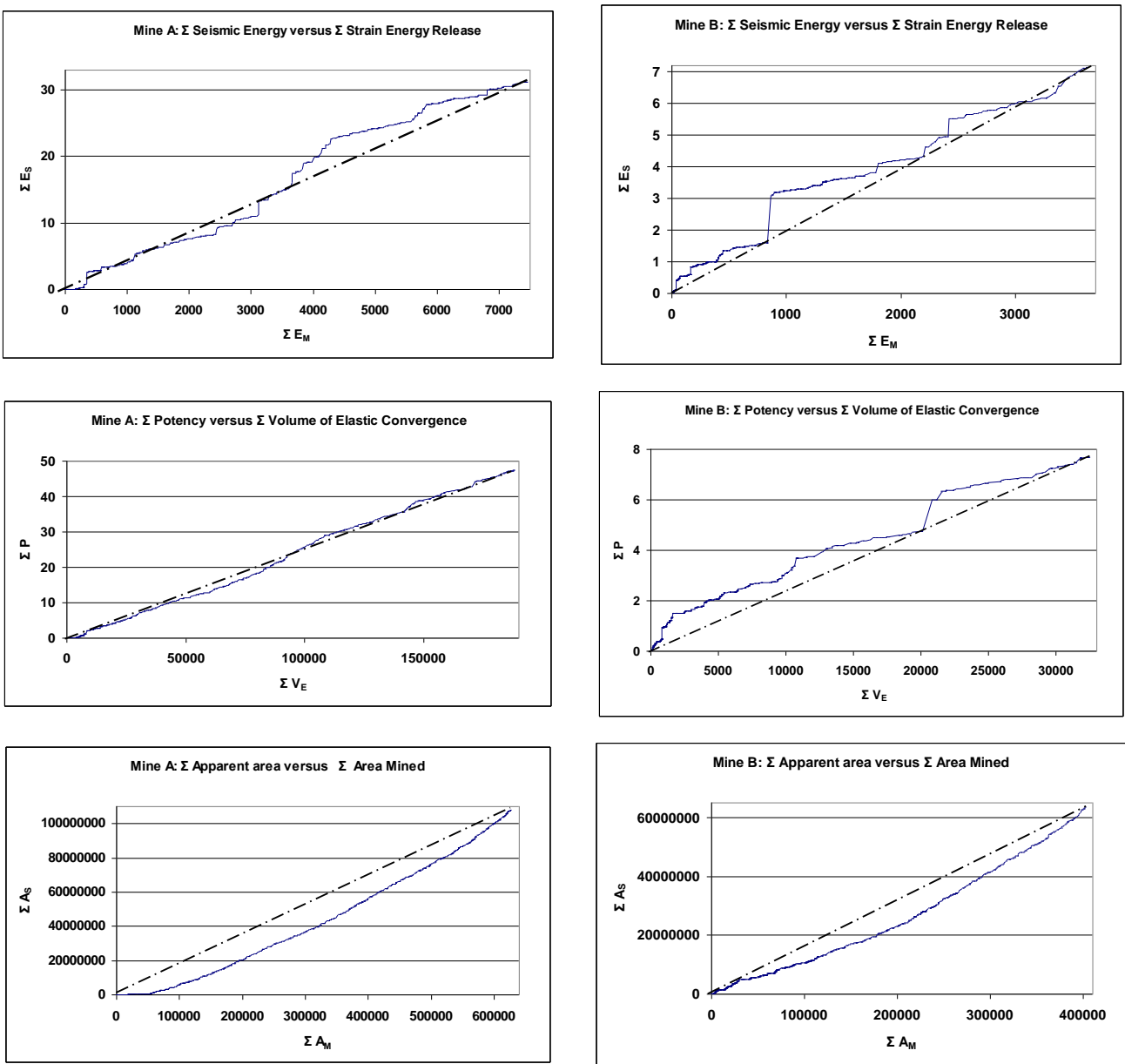

Mine A

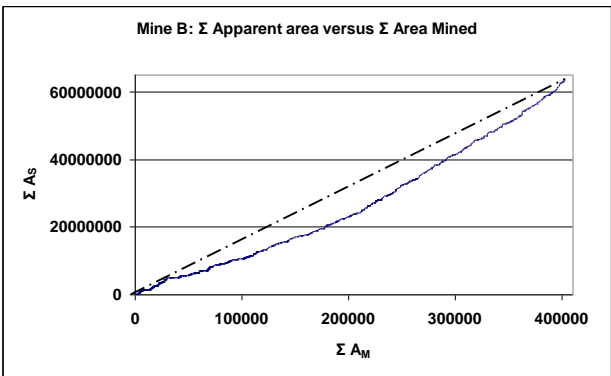

Mine B

Figure 7 Cumulated seismicity and mining. Explanation for $\mathrm{X}$ and $\mathrm{Y}$ axes listed in Table 5 
Extraction of seismic energy only from Figure 7(b) to (c) was used to show the estimates of the seismic efficiency or the proportion of released energy that was radiated seismically. The derived values of 0.4 and $0.2 \%$ for the two mines were compatible with earlier work by Spottiswoode (1980).

The estimates of $\gamma_{\mathrm{E}}$ of 0.25 and 0.19 derived from Figure 7(d) are higher than most of the values reported by Milev and Spottiswoode (1997), but substantially lower than the original work of McGarr and Wiebols (1977) who suggested that $\gamma_{E}$ should equal 1.0. As most of the values of $\gamma_{E}$ reported by Milev and Spottiswoode (1997) were less than 0.1, based on seismic moments inferred from local mine magnitudes, we suggest that the current estimates are more accurate and representative of mining on the CLR and VCR.

Figure 7(e) was introduced here to indicate the degree to which seismic events occur in the near field of one another. The degree of near-field influence amongst the suite of events is calculated by dividing the area of inferred slip by the corresponding area of mining and is called the 'overlap factor' here and has values of 73 and 67 for the two data sets (Table 5). The high degree of overlap could occur either by shear planes slipping many times or by shear planes forming close to previously formed shear planes. For comparison, the overlap factor of the shear fractures over face advance of Figure 1 from Adams et al. (2002) is about 3.2. The figures of Ortlepp (1997) yield similarly low values of overlap factor.

\section{$4 \quad$ Pillar strength}

The dip pillars were left to reduce ERR thereby resulting seismicity without themselves failing and generating excess seismicity. How would we know if they were indeed failing, given the fact that a high rate of seismicity occurs for the last stages of mining towards the pillars? If they were indeed failing, then the rate of seismicity would be even higher due to merging of the failure zones associated with each of the two faces as they approach one another. Our approach was to reduce the cap stress in our models until so much strain energy would have been released that the linear relationships between seismicity and strain energy release, apparent in Figure 7(b) to (d) was clearly lost. This appears to be the case for cap stress values of $250 \mathrm{MPa}$ and less in Figure 8 for both mines. The best estimates for pillar strength is therefore $300 \mathrm{MPa}$ or more.

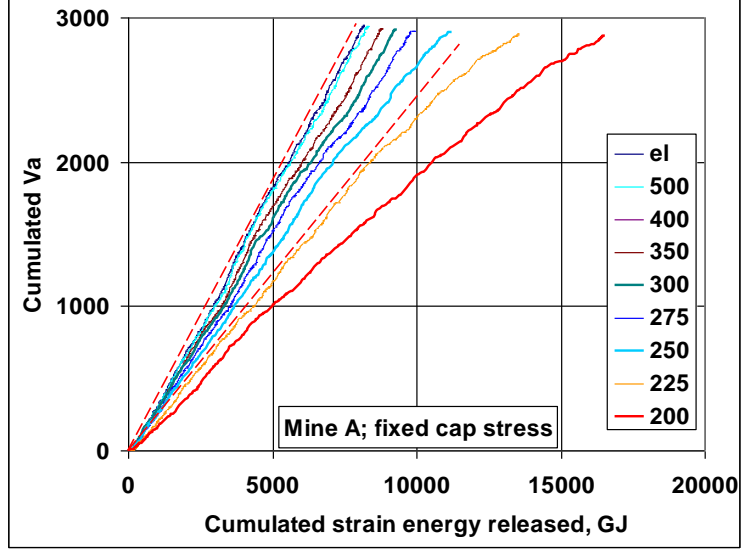

Mine A

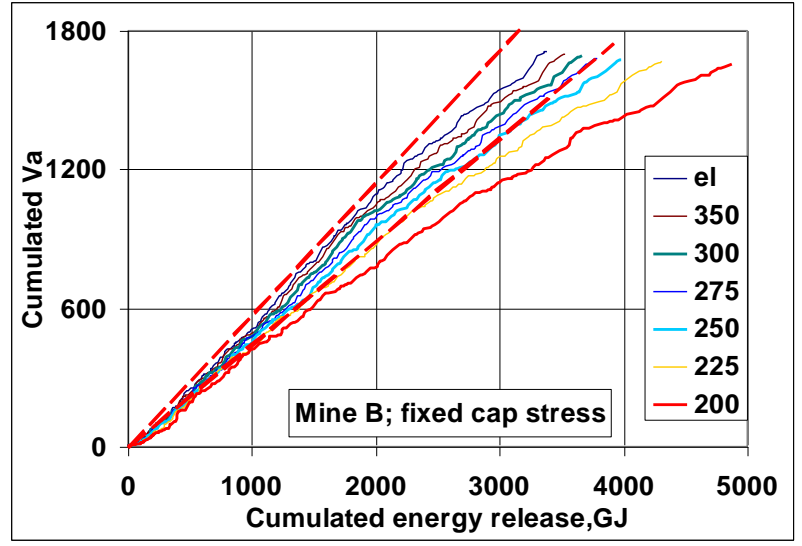

Mine B

\section{Figure 8 Effect of cap stress on strain energy release}

\section{$5 \quad$ Loading system}

Allocation of seismicity to mining faces provided the opportunity of attributing an ERR value to each of the tens of thousand of seismic events. Seismic parameters for individual events have widely scattered values and it can be difficult to identify trends in large data sets unless the trend is very clear. One commonly used approach is to bin the data and to compute statistical parameters such as the mean and median to describe the population in each bin. The type of binning applied depends on the distribution of the entire population. In the case of log-normal distributions, it is prudent to use equal numbers of samples in each bin, rather than equal intervals. The resultant data points will then have equal confidence. 
A program was written to perform the required binning and allowed the multi-parameter data sets to be explored quickly. The data for both mines was binned into 24 bins, each having an equal number of samples. For the Mine A data, each bin contained 729 samples, whereas each bin for Mine B contained 571 samples. We found some clear and unexpected variations of two parameters in particular, namely the P/S moment ratio and the apparent stress (Figure 9). Each data point represents the mean (circle) or median (solid dot) value calculated for each bin for either the P/S moment ratio or apparent stress, plotted versus the face ERR of each of the 24 bins. A purely shearing source would have a P/S moment ratio equal to one, with $\mathrm{P} / \mathrm{S}$ moment ratios greater than one indicating volume reductions in the source region.

The data from Mine B behaved as expected. The P/S moment ratio is only slightly more than one, suggesting a small influence of co-seismic stope convergence. Apparent stress versus face ERR is positively correlated, indicating that the driving stresses are higher, in agreement with increasing values of ERR.

The trends observed for the CLR (at Mine A) data are completely different from those plotted for the VCR data from Mine B and show a steady decrease from initially high values of P/S moment ratio with increasing face ERR and a decreasing value of apparent stress with increasing ERR on the CLR.

We propose a conceptual model based on the behaviour of the fracture zone to explain the seismic characteristics for the Mine A data in Figure 9 using an interpretation of Figure 1(b). The system response of the diffuse fracture zone in Figure 1(b) to slip on shear zone S2 depends strongly on the behaviour of the fracture zone. For example, the case of the fracture zone being almost completely rigid probably explains the Mine B data. A completely plastic or pliable fracture zone that provides the same strength during a seismic event as it did before the event would be no different from the case of the shear zone S1 in Figure 1(b). If the fracture zone strain hardens during an event, providing more resistance, then a fracture zone that is larger at higher levels of ERR would affect both P/S moment ratios and the apparent stress. The P/S moment ratios would increase as the shear zone becomes more isolated from the stope. Similarly, the apparent stress will decrease because the yielding fracture zone will reduce the rate of slip on the shear zone through providing a softer loading system.

(a)

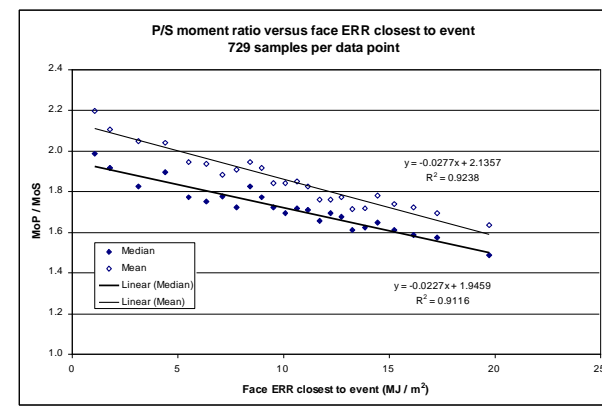

(b)

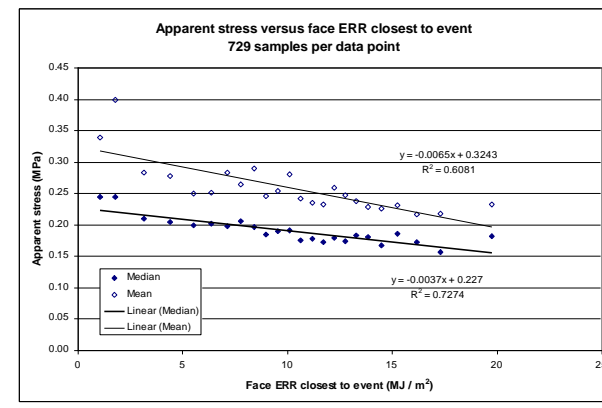

Mine A
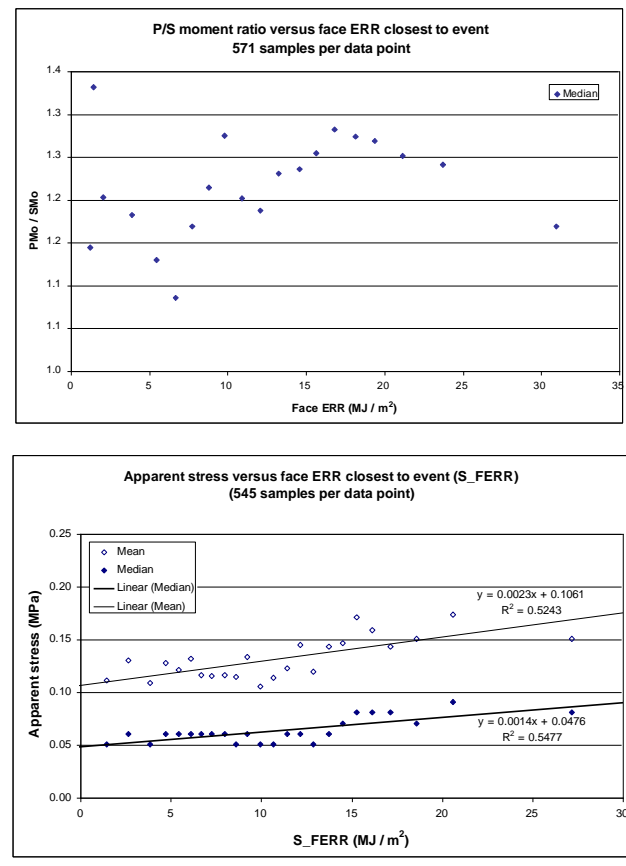

Mine B

Figure 9 Dependence of ratios of moments estimated from P-waves and S-waves (a) and apparent stress (b) as a function of the ERR at the closest active face

The cap model in MINF can be used to estimate face stiffness, as illustrated in Figure 10. In this hypothetical example, deformations in the fracture zone add to those on the element being mined to reduce the loading stiffness that advances the fracture zone. 

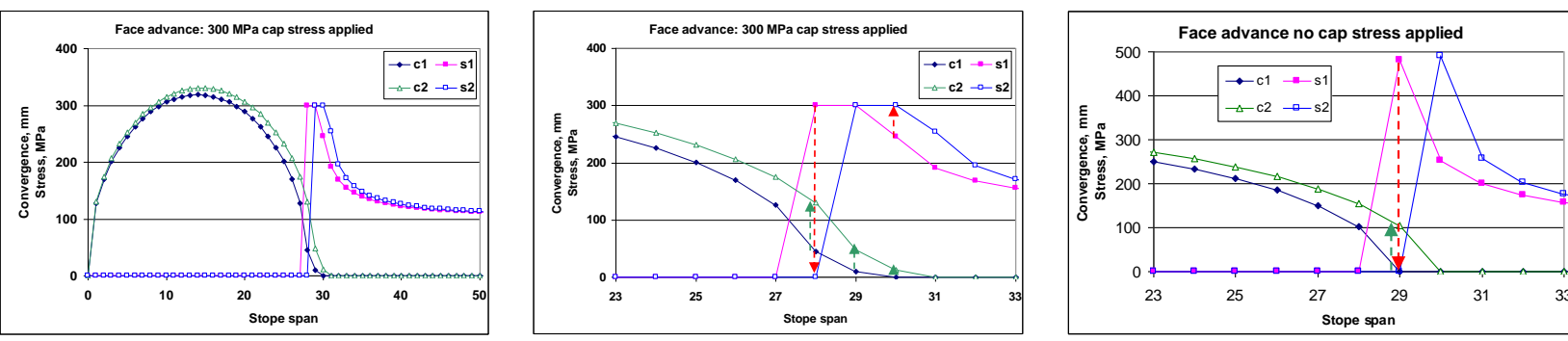

Figure 10 Diagram showing calculations involved when estimating face stiffness measured associated with face advance of an infinitely long longwall. $\mathrm{C} 1$ and $\mathrm{C} 2$ are stope convergence for two stages of mining and $S 1$ and $S 2$ are the equivalent stress values ahead of the face

Table 6 Calculations of loading system stiffness illustrated in Figure 10. A is the area of a single element, or $36 \mathrm{~m}^{2}$ in this study

\begin{tabular}{lccccc}
\hline Distance from Face & 0 & 1 & 2 & Totals & No Cap: Elastic \\
\hline$\Delta \sigma, \mathrm{MPa}$ & 300 & 0 & -54.5 & 245.5 & 480.3 \\
$\Delta \mathrm{D}, \mathrm{m}$ & 0.086 & 0.038 & 0.012 & 0.136 & 0.103 \\
Stiffness = (A x $\Delta \sigma) / \Delta \mathrm{D}$ & & & & $65 \mathrm{MPa} / \mathrm{m}$ & $169 \mathrm{MPa} / \mathrm{m}$ \\
\hline
\end{tabular}

Stiffness was calculated for each auto-poly by dividing the sum of all force changes in each poly by the sum of all the deformations on mined elements and ahead of the face for face advance of one element. The forces and deformations are illustrated in Figure 10. Figure 11 shows results for data from Mine A, suggesting that a loading stiffness model might explain the behaviour of the seismicity associated with increasing fracturing ahead of CLR stopes at bigger spans and increasing ERR.
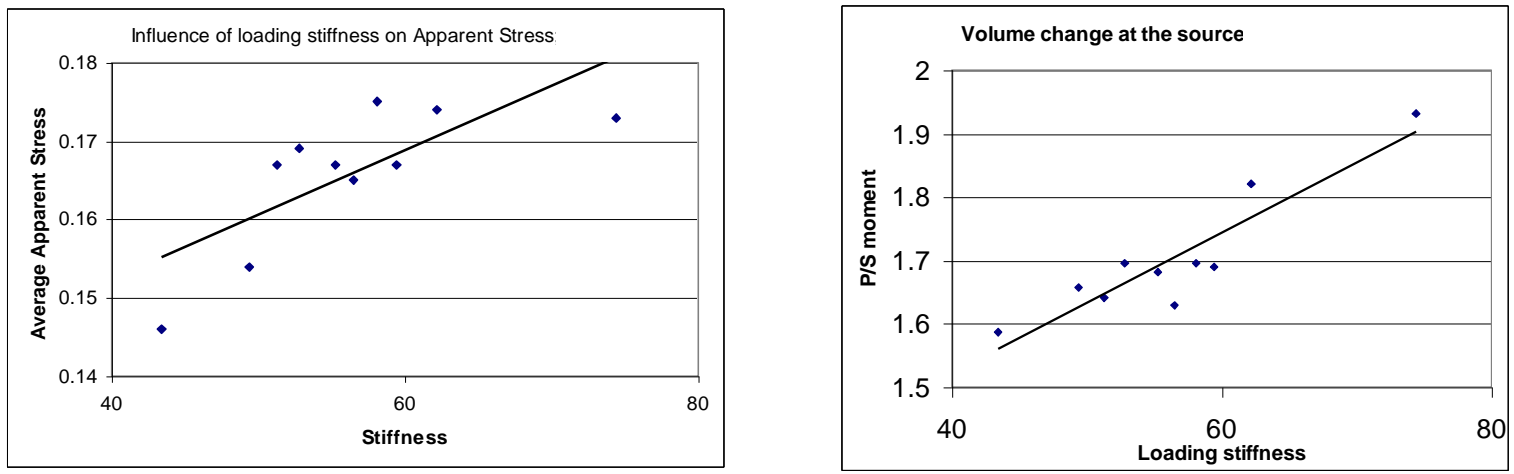

Figure 11 Apparent stress and $\mathrm{P} / \mathrm{S}$ moment ratios as a function of loading stiffness at Mine $\mathrm{A}$ for a cap stress of $300 \mathrm{MPa}$

\section{Conclusion}

ERR is, on average, a good measure of likely seismicity as measured using a range of parameters such as number of events with magnitude $(\mathrm{M})>0$, apparent volume, seismic moment and radiated energy. In effect, the averaging process also distributed the contributions of the geological structures to the total seismicity. These were quantified in a parallel study and were found to contribute at most $50 \%$ to the total amount of seismicity in the study areas.

The pillar strengths at the Mine A and Mine B sites are at least $300 \mathrm{MPa}$. Application of a cap stress of $300 \mathrm{MPa}$ and above to simulate face and pillar strength increased the values of ERR only slightly above the ERR calculated assuming infinite rock strength. Once a cap stress of less than $300 \mathrm{MPa}$ was applied in the 
models was significantly more strain energy released on the pillars than was observed. This vindicates the conservative assumption of pillar strength of $400 \mathrm{MPa}$ that was made for one of the mines.

The character of seismicity changed with increasing extent of mining. The VCR mining showed increasing values of apparent stress for increasing levels of ERR, as was expected. The ratio of seismic moment derived from $\mathrm{P}$-waves to the moment derived from $\mathrm{S}$-waves was slightly more than 1.0, compatible with a small volume change in the source region in agreement with co-seismic stope convergence. The CLR mining showed a completely different pattern of behaviour from that shown by the VCR mining, with both the apparent stress and the P/S moment ratios decreasing with increasing values of ERR. CLR mining is surrounded by a more mobile fracture zone than is the case for VCR mining. We propose a model in which CLR seismicity occurs as shear slip in the front of a fracture zone. Coseismic deformation of this fracture zone results in a loading system that slows the shear slip, reducing the apparent stress, and isolates the slip from the stope, decreasing the relative amount of stope convergence.

\section{Acknowledgements}

Thanks to Johan Klokow, Frans Castelyn, Faan Mulder, Rob McGill and Riaan Carstens for discussions on mining aspects and Rick Ferreira and Marie Gerenger for supplying the seismic data and mine plans. John Napier, John Ryder, Dave Roberts, Daniel de Carcenac and Frans Castelyn provided thoughtful reviews. This paper was supported by the South African Mine Health and Safety Council (MHSC) under project SIM04-03-01.

\section{References}

Adams, G.R., Jager, A.J. and Roering, C. (1981) Investigation of rock fracture around deep-level gold mine stopes. Proc. 22nd US Symp. Rock Mech., pp. 213-218.

Boettcher, M.S., McGarr, A., Durrheim, R.J., Spottiswoode, S., Milev, A., Linzer, L., Johnston, M.J.S. and Sell, R.W. (2008) A broadband, wide dynamic range investigation of earthquakes in deep South African gold mines, abstract, Seismological Research Letters, Vol. 79, No. 2, p. 311.

Cook, N.G.W., Hoek, E., Pretorius, J.P.G., Ortlepp, W.D. and Salamon, M.D.G. (1966) Rock Mechanics applied to rockbursts. Journal of the South African Institute for Mining and Metallurgy, pp. 435-714.

Handley, M.F., De Lange, J.A.J., Essrich, F. and Banning, J.A. (2000) A review of Sequential Grid Mining method employed at Elandsrand Gold Mine. Journal of the South African Institute for Mining and Metallurgy, Vol. 100, No. 3, pp. 157-168.

Jager, A.J. and Ryder, J.A. (1999) A Handbook on Rock Engineering Practice for tabular hardrock mines. SIMRAC, Johannesburg.

Kgarume, T. and Spottiswoode, S.M. (2008) Temporal and special behaviour of mine aftershocks density and event rate, unpublished presentation at ISSI 2008 Symposium.

Klokow, J.W., Riemer, K.L. and Ferreira, R.I. (2003) An initial assessment of the closely spaced dip - pillar mining layout as practiced at Driefontein Gold Mine. ISRM 2003 Technology roadmap for rock mechanics, S.A. Inst. Min. Metall., pp. 655-633.

Malan, D.F., Napier, J.A.L. and Grave, M. (2003) Experiments on stope closure as a diagnostic measure of rock behaviour. ISRM 2003-Technology roadmap for rock mechanics, South African Institute of Mining and Metallurgy, pp. 795-801.

McGarr, A. and Wiebols, G.A. (1977) Influence of Mine Geometry and closure volume on Seismicity in deep level mine. Int. J. Rock Mech. Min. Sci. and Geomech. Abstr., Vol. 14, pp. 139-145.

McGarr, A., Spottiswoode, S.M., Gay, N.C. and Ortlepp, W.D. (1979) Observations relevant to seismic driving stress, stress drop, and efficiency. J. Geophys. Res., 84, pp. 2251-2261.

McGill, R.B. (2005) Strategies to manage seismicity in a deep VCR environment on Mponeng, 6th Intl Symposium on Rockbursts and Seismicity in mines, Perth, Australia, pp. 419-424.

Milev, A. and Spottiswoode, S.M. (1997) Integrated seismicity around deep-level stopes in South Africa. Int. J. Rock Mech. and Min. Sci., Vol. 34, No. 199, pp. 3-4.

Napier, J.A.L. (1991) Energy changes in a rock mass containing multiple discontinuities. J. S. Afr. Inst. Min. Metall., Vol. 91, pp. 145-157.

Ortlepp, W.D. (1997) Rock Fracture and Rockbursts: an illustrative study. Monograph series M9. South African Inst. Min. Metall., 220 p.

Ryder, J.A. and Jager, A.J. (editors) (2002) A textbook on Rock Mechanics for tabular hard rock mines. 1st Edition, SIMRAC, Johannesburg, p. 233; p. 239. 
Share, P-E. (2007) Dynamic and Quasi-static Deformations of the Rocks Derived from Underground Seismic and Tilt Data, Geophysics Honours Project, University of Witwatersrand.

Spottiswoode, S.M. (1980) Thesis: Source Mechanism Studies on Witwatersrand Seismic Events, unpublished PhD thesis, University of the Witwatersrand.

Spottiswoode, S.M. (1997) Energy Release rate with limits to on-reef stress Proc. 1st Southern African Rock Engineering Symposium, R.G. Gurtunca and T.O. Hagan (editors), SANGORM, pp. 252-258.

Spottiswoode, S.M. (2001) Keynote address: Synthetic seismicity mimics observed seismicity in deep tabular mines. 5th Intl Symposium on Rockbursts and Seismicity in mines, S.A. Inst. Min. Metall., pp. 371-378.

Spottiswoode, S.M. (2005) Mine Layout Design and Medium-term Prediction of Seismicity, 5th Intl Symposium on Rockbursts and Seismicity in Mines, Perth, Australia, pp. 211-218.

Spottiswoode, S.M., Scheepers, J. and Ledwaba, L. (2006) Pillar seismicity in the Bushveld Complex, in Facing the Challenges, South African National Institute of Rock Engineering, pp. 140-158.

Toper, A.Z. (2007) Destressing/Preconditioning to Control Rockbursts in South African Deep-Level Gold Mines, in Challenges in Deep and High Stress Mining, Australian Centre of Geomechanics, pp. 503-515.

van Antwerpen, H.E.F. and Spengler, M.G. (1982) The effect of mining-related seismicity on excavations at East Rand Propriety Mines, Limited. 1st Intl. Symposium on Rockbursts and Seismicity in Mines, Johannesburg, S. Afr. Inst. of Min. Metall., pp. 29-37.

van Aswegen, G. (2005) Routine seismic hazard assessment in South African mines. 6th Intl Symposium on Rockbursts and Seismicity in Mines, Perth, Australia, pp. 437-444. 
